\title{
Quantitative Atom Probe Analysis of Carbides
}

\author{
M. Thuvander ${ }^{*}$, J. Weidow ${ }^{1}$, J. Angseryd ${ }^{1,2}$, L.K.L. Falk ${ }^{1}$, F. Liu ${ }^{1}$, M. Sonestedt ${ }^{1}$, \\ K. Stiller ${ }^{1}$, H.-O. Andrén ${ }^{1}$ \\ 1- Chalmers University of Technology, Göteborg, Sweden \\ 2-Sandvik Tooling, Stockholm, Sweden \\ *corresponding author: mattias.thuvander@chalmers.se
}

Compared to atom probe analysis of metallic materials, the analysis of carbide phases results in an enhanced formation of molecular ions and multiple events. In addition, many multiple events appear to consist of two or more ions originating from adjacent sites in the material. Due to limitations of the ion detectors measurements generally underestimate the carbon concentration. Analyses using laser pulsed atom probe tomography have been performed on $\mathrm{SiC}, \mathrm{WC}, \mathrm{Ti}(\mathrm{C}, \mathrm{N})$ and $\mathrm{Ti}_{2} \mathrm{AlC}$ grains in different materials as well as on large $\mathrm{M}_{23} \mathrm{C}_{6}$ precipitates in steel. Using standard evaluation methods, the obtained carbon concentration is 6-24\% lower than expected from the known stoichiometry. The results improve remarkably by using only the ${ }^{13} \mathrm{C}$ isotope, and calculating the concentration of ${ }^{12} \mathrm{C}$ from the natural isotope abundance. This confirms that the main reason for obtaining a too low carbon concentration is the dead time of the detector, mainly affecting carbon since it is more frequently evaporated as multiple ions. In the case of $\mathrm{Ti}(\mathrm{C}, \mathrm{N})$ and $\mathrm{Ti}_{2} \mathrm{AlC}$ an additional difficulty arises from the overlap between $\mathrm{C}_{2}{ }^{+}, \mathrm{C}_{4}{ }^{2+}$ and $\mathrm{Ti}^{2+}$ at the mass-to-charge $24 \mathrm{Da}$.

Keywords; Atom probe, Atom probe tomography, Carbides, Quantitative analysis

\section{Introduction}

Atom probe is the only technique capable of detecting light (boron, carbon) as well as heavy (tungsten, niobium, tantalum) elements with an equal sensitivity. Therefore, already in the early seventies, the method was proposed as suitable and used for studies of carbides in a number of different systems, see for 
example [1-6]. However, in many studies the measured carbon content appears to be lower than expected so the question arises, how accurately can carbon be quantified?

Compared to analysis of metallic materials, atom probe analysis of carbide phases results in an enhanced formation of molecular ions and multiple events where more than one ion originating from the same pulse is detected [7]. This may be due to a high ionization energy of carbon [8] and/or because the difference between metallic bonding and the bonding between adjacent carbon atoms or carbon and metal atoms. As a result carbon will evaporate at a higher electric field, which may cause its retention on the specimen surface and stimulate the occurrence of multiple events. The large amount of such events puts high demands on the performance of the detector, in particular on the dead time, and may lower the "detection efficiency" for carbon. This problem was recently also recognized by Yao et al. [9].

We have for a long time corrected individual peaks in the mass spectrum for the detector dead time using the Rolander ion pair correction algorithm in the 1-D atom probe [10]. This was accomplished by a statistical approach making use of multiple events detected, i.e. multiple events separated by a time longer than the dead time, and then calculating the amount of lost ions. In the 3-D atom probe this method cannot easily be used since time and space are coupled. Two ions arriving at the position sensitive detector exactly at the same time can easily be recorded if they are well separated in space. Unfortunately, when several ions are field evaporated during the same pulse, they will most probably be close in space, making detection more difficult. As most of the pulses do not generate any ions, it is unlikely that one pulse causes ions far from each other to field evaporate because they cannot influence each other at a large separation. Here we will present other possibilities of correcting the missing carbon in atom probe analyses.

\section{Materials and methods}


Five carbide materials are included in this study; $\mathrm{Ti}(\mathrm{C}, \mathrm{N}), \mathrm{Ti}_{2} \mathrm{AlC}, \mathrm{WC}, \mathrm{SiC}$ and $\mathrm{M}_{23} \mathrm{C}_{6}$. The first four materials can be considered as bulk carbides, whereas $\mathrm{M}_{23} \mathrm{C}_{6}$ was found as a relatively large precipitate in a creep resistant steel.

The $\operatorname{Ti}(\mathrm{C}, \mathrm{N})$ material was produced from $\mathrm{Ti}\left(\mathrm{C}_{0.7} \mathrm{~N}_{0.3}\right)$ powder that was pressed and sintered at a high pressure and high temperature, around $5 \mathrm{GPa}$ and $1500^{\circ} \mathrm{C}$. Chemical bulk analysis has shown the composition to be 33.1 at.\% C - 15.9 at.\% $\mathrm{N}-1.2$ at.\% 0 (balance Ti) [11]. Titanium carbonitrides in cermets have previously been analyzed using voltage pulsed 1-D atom probe $[4,12]$, where the effect of the detector dead time was addressed. In the case of cermets the carbides are surrounded by a metallic binder phase making them easier to analyze.

The analyzed $\mathrm{Ti}_{2} \mathrm{AlC}$ is the major phase in bulk Maxthal ${ }^{\circledR} 211$ from Kanthal $\mathrm{AB}$, Sweden. It posses both metallic and ceramic properties due to its layered structure consisting of $\mathrm{Ti}_{2} \mathrm{C}$ layers separated by individual Al layers. This phase has not been analyzed using atom probe before. Further details are presented by Sonestedt et al. in this issue [13].

The WC analyzed is the dominating constituent in a WC-NbC-Co sintered cemented carbide material. $\mathrm{NbC}$ additions are made to the powder mixture in order to decrease crater wear when used as a tool material. A detailed description of the material production can be found elsewhere [14]. WC is believed to be a stoichiometric compound. It has previously been analyzed using voltage pulsed 1-D atom probe [5].

The liquid phase sintered silicon carbide ceramic was fabricated with the addition of $3 \mathrm{wt} \% \mathrm{Al}_{2} \mathrm{O}_{3}$ and $\mathrm{Y}_{2} \mathrm{O}_{3}$ and hot isostatically pressed at $1800^{\circ} \mathrm{C}$ for $2 \mathrm{~h}$ under a pressure of $160 \mathrm{MPa}$. $\alpha$-SiC grains, with the $6 \mathrm{H}$ or $4 \mathrm{H}$ polytype, were surrounded by an yttrium, aluminium and oxygen rich residual glass present as thin $(\sim 1.5 \mathrm{~nm})$ grain boundary films merging into pockets at multi grain junctions [15]. Silicon carbide has previously been studied using laser pulsed 1-D [16] and 3-D atom probe [17]. 
The $\mathrm{M}_{23} \mathrm{C}_{6}$ precipitate studied was present in a high-boron (300 ppm) martensitic $10.5 \%$ chromium steel containing $0.21 \%$ C, $1.5 \% \mathrm{Mo}, 0.24 \% \mathrm{~V}$ and $0.18 \% \mathrm{Nb}(\mathrm{wt} \%)$. The steel was austenitized at $1150^{\circ} \mathrm{C}$ for $1 \mathrm{~h}$ and tempered at $700^{\circ} \mathrm{C}$ for $2 \mathrm{~h}$, and was studied in the as-tempered state. Of course, many atom probe studies have been carried out on carbides in steels [18] using both 1-D and 3 - $\mathrm{D}$ atom probe, mostly using voltage pulsing. The alloy carbide $\mathrm{M}_{23} \mathrm{C}_{6}$ in creep resistant $9-12 \% \mathrm{Cr}$ steel has for example been studied by Lundin and Andrén [19].

All materials were analyzed using a local electrode atom probe (Imago LEAP 3000X HR) equipped with a reflectron for improved mass resolution. The detection efficiency is about $37 \%$ and the dead time of the delay-line detector is less than 3 ns, as stated by the supplier. The analyses were carried out in laser pulse mode with a wavelength of $532 \mathrm{~nm}$. At least in the case of $\mathrm{M}_{23} \mathrm{C}_{6}$ and WC voltage pulsing is of course also possible. However, the success rate and the analysis length appear to be clearly higher when using laser pulsing. As a comparison WC was additionally analyzed using voltage pulse mode. The analysis parameters are listed in table 1.

Atom probe samples of $\mathrm{Ti}(\mathrm{C}, \mathrm{N}), \mathrm{Ti}_{2} \mathrm{AlC}, \mathrm{SiC}$ and $\mathrm{M}_{23} \mathrm{C}_{6}$ were prepared using the focused ion beam (FIB) lift-out technique [20]. In the case of $\mathrm{M}_{23} \mathrm{C}_{6}$ the steel sample had to be carefully ion milled until a carbide could be observed close to the tip apex. Needle samples of WC were prepared by a combination of electropolishing and FIB [21]. In all cases the final milling was carried out using a lower voltage $(5 \mathrm{kV})$ to limit Ga implantation.

\section{Results and Discussion}

\subsection{Mass spectra}

In all cases, except for $\mathrm{SiC}$, the atom probe analyses resulted in mass spectra of high quality. The mass resolving power ranges from 350 to above 700 (FWHM). The usual broad peak tails (towards higher mass-to-charge ratios) are reasonably small and the formation of molecular ions typical for laser pulsing is 
not excessive. Results from analyses of all materials are found in table 2 . In the case of $\mathrm{SiC}$ good analyses have not been achieved. The peaks are very broad and have large tails, see the mass spectrum in figure 1, giving poor values of FWHM and FWTM, similar to values in older 1-D work [16] as well as in very recent analyses [17]. The analysis is, however, still useful, and the measurement of the boron content of the carbide is probably correct. Perhaps improved results can be obtained using lower laser pulse energy or specimen temperature. However, this would increase the already high risk of premature specimen fracture.

Two mass spectra of WC are presented in figure 2, one obtained using laser pulsing and one using voltage pulsing. The effect of an increased evaporation field in the voltage pulsed analysis, despite the $30 \mathrm{~K}$ higher base temperature, results for example in the formation of $\mathrm{C}^{3+}$. The mass resolution and background noise level are very good and similar in the two cases.

The evaporation fields in the analyses were estimated from the charge state curves of Kingham [22]. Ti(C,N), $\mathrm{Ti}_{2} \mathrm{AlC}$ and $\mathrm{M}_{23} \mathrm{C}_{6}$ gave values of $37-38 \mathrm{~V} / \mathrm{nm}$ using the ratio of $\mathrm{Ti}^{3+} / \mathrm{Ti}^{2+}$ in the titanium based carbides and the ratio of $\mathrm{Mo}^{3+} / \mathrm{Mo}^{2+}$ in $\mathrm{M}_{23} \mathrm{C}_{6}$. In the case of $\mathrm{SiC}$ the evaporation field was estimated using the ratio $\mathrm{Ga}^{2+} / \mathrm{Ga}^{+}$from FIB implanted gallium. The value obtained was $28 \mathrm{~V} / \mathrm{nm}$, which in turn implies that the fraction of $\mathrm{Si}^{+}$should be extremely small $\left(<10^{-4}\right)$ and therefore the peak at $28 \mathrm{Da}$ is perhaps not $\mathrm{Si}^{+}$but $\mathrm{SiCO}^{2+}$ or $\mathrm{CO}^{+}$. The evaporation field of WC was estimated from the $\mathrm{W}^{4+} / \mathrm{W}^{3+}$ ratio to be $48 \mathrm{~V} / \mathrm{nm}$ and $50 \mathrm{~V} / \mathrm{nm}$ for laser pulsed and voltage pulsed analyses, respectively. The applicability of the Kingham curves when using laser pulsing is probably more limited than when using voltage pulsing, as the amount of molecular ions is higher. The molecular ions will behave differently during post-ionization, affecting the charge state distribution (assuming that molecular ions often split during the process and end up as atomic ions).

Carbon is present in the mass spectrum at a number of peaks, as summarized in table 3. In all cases $\mathrm{C}^{2+}$ is the largest, and the only other non-molecular ion, $\mathrm{C}^{+}$, also accounts for a large fraction of the detected carbon. In the laser pulsed 
analyses the ratio $\mathrm{C}^{2+} / \mathrm{C}^{+}$ranges from 1.2 for $\mathrm{Ti}(\mathrm{C}, \mathrm{N})$ to 2.0 for $\mathrm{WC}$. The ratio is still higher for voltage pulsed WC (2.8), which is also the only case where $\mathrm{C}^{3+}$ is observed in any significant amount, in agreement with the field being higher. Regarding molecular ions, they account for about half the detected carbon for $\mathrm{Ti}(\mathrm{C}, \mathrm{N})$, SiC and $\mathrm{M}_{23} \mathrm{C}_{6}$, whereas only $16 \%$ originate from molecular ions in $\mathrm{Ti}_{2} \mathrm{AlC}$. In analyses of WC the molecular ions constitute a very small fraction, in particular in the voltage pulsed analysis. By comparing the different materials, no simple conclusion can be made as far as the fraction of molecular carbon ions is concerned. Probably the tendency to form molecular ions decreases with increasing evaporation field and decreasing carbon concentration. However, these effects do not fully explain the observed distributions, which indicates that the chemical bonding and/or the carbon sites in the carbide lattice are also of importance.

In all analyses the number of multiple events is very high. This means that more than one ion originating from the same pulse are detected. The fraction of multiple events range from $30 \%$ in the material of lowest carbon content $\left(\mathrm{M}_{23} \mathrm{C}_{6}\right)$ to $60 \%$ in voltage pulsed WC. This behavior is typical of carbides, which field evaporate in an irregular fashion [4]. The effect of multiple events together with detector dead time is largest if there is only one (or a few) dominating peaks of an element. Hence, the situation improves if there are several charge-states and many isotopes of reasonable abundance. In the case of carbon there are usually several charge-states and some molecular ions, but there is only one dominating isotope $\left(98.93 \pm 0.08 \%{ }^{12} \mathrm{C}\right.$ and $\left.1.07 \pm 0.08 \%{ }^{13} \mathrm{C}[\mathrm{NEW}]\right)$. Furthermore, it could be concluded from comparing mass spectra of single events and multiple events that carbon is much more common in the multiple events than other elements, as shown in figure 3 . The effect of the dead time obviously gets more severe when the mass resolution is high, as the time spread between two ions of the same mass-to-charge ratio coming from the same pulse is small (in particular it is smaller than the dead time). This also implies that the loss of carbon atoms becomes higher when the voltage increases during an analysis. 
The chemical compositions obtained using standard mass spectrum evaluation are presented in table 2 . It is clear that in all cases the carbon concentration is too low.

\section{$3.2{ }^{13} \mathrm{C}$-Method}

It was observed in all analyses that the ${ }^{13} \mathrm{C}$ peaks at mass-to-charge ratios 6.5 and 13 Da were larger than what is expected from the natural abundance. This can be understood because the effect of the dead time is much stronger for large peaks $\left({ }^{12} \mathrm{C}\right)$ than for small peaks $\left({ }^{13} \mathrm{C}\right)$. Hence, the ${ }^{13} \mathrm{C}$ isotope can be used to calculate how much carbon should be present at m/q 6 and $12 \mathrm{Da}$, assuming that the dead time has negligible influence on the ${ }^{13} \mathrm{C}$ peaks. The number of counts detected at m/q 6.5 Da is multiplied by 92.5 to give the corrected number of counts at m/q $6 \mathrm{Da}$. In the same way the number of counts detected at m/q $13 \mathrm{Da}$ is multiplied by 92.5 to give the corrected number of counts at m/q $12 \mathrm{Da}$. When performing this correction it is very important to make a careful background subtraction, so that the background is not being multiplied. In the examples shown in figure 2 , the signal to noise ratios of the ${ }^{13} \mathrm{C}$ peaks are larger than 100. The resulting carbon concentrations, after background subtraction and correction of the $\mathrm{C}^{+}$and $\mathrm{C}^{2+}$ peaks using ${ }^{13} \mathrm{C}$, are given in table 4 . Obviously the corrected carbon concentrations are much closer to the expected values. Unfortunately, the method could not be applied to $\mathrm{SiC}$ because of the large peak tails.

As just mentioned, the ${ }^{13} \mathrm{C}$-method gives a more correct carbon concentration. On the other hand the uncertainty increases. Firstly, the uncertainty from the counting statistics is studied using $\mathrm{C}^{+}$in the relatively short analysis of $\mathrm{Ti}_{2} \mathrm{AlC}$. The concentration of $\mathrm{C}^{+}$changes from $8.01 \pm 0.05$ at. $\%$ to $11.56 \pm 0.55$ at. $\%$, when applying the ${ }^{13} \mathrm{C}$-method. Hence, the uncertainty originating from the counting statistics is increased by a factor of 10 . It is clear that the analysis must contain a sufficient number of ions for the method to be useful (say 100,000 or so). Secondly, the uncertainty arising from the terrestrial variation in isotope abundance gives a substantial standard deviation of 0.9 at.\% for the $\mathrm{C}^{+}$peak in this example. Thirdly, the importance of the background subtraction becomes 
much more important when using the ${ }^{13} \mathrm{C}$ peaks for quantification. In the previous example about $8 \%$ of the ions in the m/q 13 Da peak were taken as background. In order to make a first rough estimate of the sensitivity of the method, a background of 7\% could be used. This would give the concentration of $\mathrm{C}^{+}$as 11.66 at.\%. If instead the background level is halved (which would clearly be an incorrect background correction), the concentration of $\mathrm{C}^{+}$gets 12.1 at.\%. All in all, the effect of counting statistics, terrestrial variation in isotope abundance and background subtraction on the uncertainty are tolerable. When adding the uncertainty in the example above the result becomes $11.6 \pm 1.7$ at.\%, The relatively large uncertainty originating from the variation in isotope abundance will be a systematic uncertainty within one material or production lot. In principle, a way to decrease the uncertainty would be to determine the isotope distribution of the bulk of the material to be investigated using mass spectrometry.

A further effect that could potentially be severe would be the formation of hydride molecular ions, such as $\mathrm{CH}^{+}$and $\mathrm{CH}^{2+}$. If there would be an appreciable amount of these ions the carbon concentration could be strongly overestimated. However, no cases have been encountered where the ${ }^{13} \mathrm{C}$ method has given unrealistically high $\mathrm{C}$ concentrations in this work, suggesting that $\mathrm{CH}$ is not a problem.

\subsection{The 24 Da peak}

In the titanium containing carbides, the isotope correction scheme does not work for the peak at $24 \mathrm{Da}$, consisting of $\mathrm{Ti}^{2+}$ and $\mathrm{C}_{2}{ }^{+}$and perhaps also $\mathrm{C}_{4}{ }^{2+}$. When performing peak decomposition using the natural abundance of the four minor titanium isotopes, the result is that there is no carbon in the 24 Da peak. In fact, the peak is too small even if the carbon is zero. This is most certainly a consequence of multiple events and the dead time of the detector, strongly affecting the $24 \mathrm{Da}$ peak. The amount of $\mathrm{C}_{2}{ }^{+}(24 \mathrm{Da})$ is larger than the amounts of both $\mathrm{C}_{3}{ }^{+}(36 \mathrm{Da})$ and $\mathrm{C}_{3}{ }^{2+}(18 \mathrm{Da})$ in laser pulsed analyses of the titanium free carbides $\mathrm{WC}, \mathrm{SiC}$ and $\mathrm{M}_{23} \mathrm{C}_{6}$, see table 3. Therefore, it is almost certain that the analyses of $\mathrm{Ti}(\mathrm{C}, \mathrm{N})$ and $\mathrm{Ti}_{2} \mathrm{AlC}$ should contain significant amounts of carbon at 24 
Da (probably a few at.\%). A method for estimating the amount of carbon at $24 \mathrm{Da}$ based on comparison of peaks in single event and multiple event spectra has been proposed by Angseryd et al. [11]. After applying the ${ }^{13} \mathrm{C}$ method, Ti(C,N) lacks about 3 at. $\% \mathrm{C}$, which is probably attributed to $\mathrm{C}_{2}+$ or $\mathrm{C}_{4}{ }^{2+}$ ions, whilst the carbon concentration of $\mathrm{Ti}_{2} \mathrm{AlC}$ is not too low and if carbon is further added from the 24 Da peak the apparent carbon concentration becomes too high. The reason for this is probably that also the aluminum concentration is too low, because of multiple events and the dead time. As Al only has one isotope and a majority of $\mathrm{Al}$ is field evaporated as $\mathrm{Al}^{2+}$ it could easily be affected by the dead time. This is further dealt with in a paper by Sonestedt in this issue [13].

The peak at $24 \mathrm{Da}$, in the absence of Ti, is usually assigned to $\mathrm{C}_{2}{ }^{+}$but it has also been reported that a large part of the peak may be $\mathrm{C}_{4}{ }^{2+}[23]$. In the latter case there will be a small peak at 24.5 $\mathrm{Da}$, corresponding to one of the four $\mathrm{C}$ atoms being ${ }^{13} \mathrm{C}$. The size of the 24.5 Da peak will then be 4/92.5 of the 24 Da peak. From the analysis of $\mathrm{M}_{23} \mathrm{C}_{6}$, where there is virtually no $\mathrm{Ti}$, the mass resolution is high and the 24 Da peak is large, the amount of $\mathrm{C}_{4}{ }^{2+}$ can be estimated. The number of counts at 24 Da and 24.5 Da were 4903 and 115, respectively, giving the fraction $\mathrm{C}_{4}{ }^{2+} / \mathrm{C}_{2}+$ ions at $24 \mathrm{Da}$ as large as 1.2 , and in terms of atoms the ratio is doubled. This is similar to what has been reported for martensitic steel [23]. This topic is further treated in reference [24]. The carbon deficit in the analysis of $\mathrm{SiC}$ can perhaps be attributed to $\mathrm{C}_{4}{ }^{2+}$, even though at the low field doubly charged molecular ions are less likely.

\section{Conclusions}

Five carbide materials have been investigated using laser pulsed APT. The carbon concentration obtained by standard mass spectrum evaluation was in all cases lower than expected due to multiple events and detector dead time. Improved results could be obtained using the minor isotope ${ }^{13} \mathrm{C}$ and, for titanium containing carbides, using a correction for the 24 Da peak. 


\section{References}

[1] P.J. Turner, J.M. Papazian, Some applications of field-ion atom-probe analysis to iron and steels, Met. Sci. J. 7 (1973) 81-86.

[2] A. Youle, P.J. Turner, B. Ralph, A preliminary field-ion atom-probe investigation of competitive carbide formation in ferritic steels, J. Microsc. 101 (1974) 1-8.

[3] K. Stiller, L-E. Svensson, P.R. Howell, Wang Rong, H-O. Andrén, G.L. Dunlop, High resolution microanalytical study of precipitation in a powder metallurgical high speed steel, Acta Met. 32 (1984) 1457-1467.

[4] U. Rolander, H-O. Andrén, On atom-probe analysis of cubic MX-type carbides and carbonitrides, J. Phys. (Paris) 49 (1988) 299-304.

[5] A. Henjered, M. Hellsing, H.-O. Andrén , H. Nordén, Quantitative microanalysis of carbide/carbide interfaces in WC-Co-base cemented carbides, Mater. Sci. Techn. 2 (1986) 847-855.

[6] M. Thuvander, K. Stiller, D. Blavette, A. Menand, Grain boundary precipitation and segregation in Ni-16Cr-9Fe model materials, Appl. Surf. Sci. 94/95 (1996) 343-350.

[7] H.-O. Andrén, A. Henjered, H. Nordén, Composition of MC precipitates in a titanium stabilized austenitic stainless steel, J. Mater. Sci. 15 (1980) 2365-2368.

[8] D. G. Brandon, The resolution of atomic structure: recent advances in the theory and development of the field ion microscope, Brit. J. Appl. Phys. 14 (1963) 474-484. 
[9] L. Yao, B. Gault, J. M. Cairney, S. Ringer, On the multiplicity of field evaporation events in atom probe: A new dimension to the analysis of mass spectra, Phil. Mag. Lett. 90 (2010) 121-129.

[10] U. Rolander, H.-O. Andrén, Statistical correction for pile-up in the atomprobe detector system, J. Phys. (Paris) 50-C8 (1989) 529-534.

[11] J. Angseryd, F. Liu, H.-O. Andrén, S. S. A. Gerstl, M. Thuvander, Quantitative APT investigation of Ti(C, N), This issue.

[12] J. Zackrisson, M. Thuvander, P. Lindahl, H.-O. Andrén, Atom probe analysis of carbonitride grains in $(\mathrm{Ti}, \mathrm{W}, \mathrm{Ta}, \mathrm{Mo})(\mathrm{C}, \mathrm{N})(\mathrm{Co} / \mathrm{Ni})$ cermets with different carbon content, Appl. Surf. Sci. 94/95 (1996) 351-355.

[13] M. Sonestedt, K. Stiller, Using atom probe tomography to analyse MAXphase materials, This issue.

[14] J. Weidow, J. Zackrisson, B. Jansson, H.-O. Andrén, Characterisation of WC-Co with cubic carbide additions, Int. J. Refractory Met. Hard Mater. 27 (2009) 244248.

[15] L.K.L. Falk, Microstructural development during liquid phase sintering of silicon carbide ceramics, J. Eur. Ceram. Soc. 17 (1997) 983-994.

[16] M.K. Miller, P. Angelini, A. Cerezo, K.L. More, Pulsed laser atom probe characterization of silicon carbide, J. Phys. (Paris) 50-C8 (1989) 459-464.

[17] P.R. Heck, M.J. Pellin, A.M. Davis, I. Martin, L. Renaud, R. Benbalagh, D. Isheim, D.N. Seidman, J. Hiller, T. Stephan, R.S. Lewis, M. R. Savina, A. Mane, J. Elam, F.J. Stadermann, X. Zhao, T.L. Daulton, S. Amari, Atom-probe tomographic analyses of presolar silicon carbide grains and meteoritic nanodiamonds - first results on silicon carbide, 41 st Lunar and Planetary Sci. Conf. (2010) 2112. 
[18] R. C. Thomson, Characterization of carbides in steels using atom probe fieldion microscopy, Mater. Char. 44 (2000) 219-233.

[19] L. Lundin, H.-O. Andrén, Atom-probe investigation of a creep resistant $12 \%$ chromium steel, Surf. Sci. 266 (1992) 397-401.

[20] M.K. Miller, K.F. Russell, Atom probe specimen preparation with a dual beam SEM/FIB miller, Ultramicroscopy 107 (2007) 761-766.

[21] J. Weidow, H.-O. Andrén, APT analysis of WC-Co based cemented carbides, This issue.

[22]. D.R. Kingham, The post-ionization of field evaporated ions; a theoretical explanation of multiple charge states, Surf. Sci. 116 (1982) 273-301.

[NEW]. J.K. Böhlke, J.R. de Laeter, P. De Bièvre, H. Hidaka, H.S. Peiser, K.J.R. Rosman, P.D.P. Taylor, Isotopic composition of the elements, 2001, J. Phys. Chem. Ref. Data 34 (2005) 57-67.

[23] W. Sha, L. Chang, G. D. W. Smith, Liu Cheng, E. J. Mittemeijer, Some aspects of atom-probe analysis of Fe-C and Fe-N systems, Surf. Sci. 266 (1992) 416-423.

[24] F. Liu, H.-O. Andrén, Effects of laser pulsing on analysis of steels by atom probe tomography, This issue. 
Table 1 . Experimental parameters used for LEAP analyses.

\begin{tabular}{|l|l|l|l|l|l|l|}
\hline & $\mathrm{Ti}(\mathrm{C}, \mathrm{N})$ & $\mathrm{Ti}_{2} \mathrm{AlC}$ & $\mathrm{WC}$ & $\mathrm{WC}^{\mathrm{a}}$ & $\mathrm{SiC}$ & $\mathrm{M}_{23} \mathrm{C}_{6}$ \\
\hline Laser pulse energy (nJ) & 0.3 & 0.4 & 0.35 & - & 0.5 & 0.35 \\
\hline Voltage pulse fraction (\%) & - & - & - & 20 & - & - \\
\hline Pulse frequency (kHz) & 200 & 200 & 200 & 200 & 200 & 200 \\
\hline Evaporation rate (\%) & 0.2 & 0.6 & 1 & 0.5 & 0.5 & 0.5 \\
\hline Temperature (K) & 65 & 50 & 66 & 96 & 65 & 60 \\
\hline
\end{tabular}

aVoltage pulsing. 
Table 2. Composition obtained using standard evaluation (including peak decomposition and background subtraction) together with some other parameters.

\begin{tabular}{|l|l|l|l|l|l|l|}
\hline & $\mathrm{Ti}(\mathrm{C}, \mathrm{N})$ & $\mathrm{Ti}_{2} \mathrm{AlC}$ & $\mathrm{WC}$ & $\mathrm{WC}^{\mathrm{a}}$ & $\mathrm{SiC}$ & $\mathrm{M}_{23} \mathrm{C}_{6}$ \\
\hline $\mathrm{C}$ & 26.6 & 19.9 & 47.1 & 46.2 & 45.3 & 15.2 \\
\hline $\mathrm{N}$ & 15.2 & 0.52 & 0.018 & 0.041 & & \\
\hline $\mathrm{Ti}$ & 57.8 & 54.1 & & & & \\
\hline $\mathrm{W}$ & & & 53.4 & 52.9 & & \\
\hline $\mathrm{Si}$ & & & & & 53.3 & \\
\hline $\mathrm{Al}$ & & 22.5 & & & & \\
\hline $\mathrm{O}$ & 0.15 & 3.0 & & & 1.4 & \\
\hline $\mathrm{Nb}$ & & & 0.06 & 0.48 & & \\
\hline $\mathrm{B}$ & & & & & 0.06 & 2.1 \\
\hline Cr, Fe, Mo, Mn, V, Ni & & & & & & 81.7 \\
\hline $\mathrm{C}($ expected) & 33.1 & $25 \mathrm{~b}$ & 50 & 50 & 50 & $20.7 \mathrm{c}$ \\
\hline No. of ions (×106) & 2.0 & 0.34 & 3.3 & 0.97 & 0.46 & 0.084 \\
\hline FWHM & 452 & 358 & 604 & 629 & 40 & 720 \\
\hline FWTM & 214 & 173 & 226 & 248 & 18 & 318 \\
\hline Single events (\%) & 45 & 59 & 48 & 40 & 55 & 70 \\
\hline Multiple events (\%) & 55 & 41 & 52 & 60 & 45 & 30 \\
\hline
\end{tabular}

aVoltage pulsing.

bIncluding $\mathrm{N}$ and $\mathrm{O}$.

cIncluding B. 
Table 3. Distribution of carbon in mass spectra in at.\%, normalized to $100 \%$. The mass-to-charge ratios (m/q) given relate to the ${ }^{12} \mathrm{C}$ isotope and the most abundant isotope of $\mathrm{B}, \mathrm{N}, \mathrm{Si}$, Ti and Mo, respectively.

\begin{tabular}{|c|c|c|c|c|c|c|c|}
\hline & $\begin{array}{l}\mathrm{m} / \mathrm{q} \\
(\mathrm{Da})\end{array}$ & $\operatorname{Ti}(\mathrm{C}, \mathrm{N})$ & $\mathrm{Ti}_{2} \mathrm{AlC}$ & WC & $\mathrm{WC}^{\mathrm{a}}$ & $\mathrm{SiC}$ & $\mathrm{M}_{23} \mathrm{C}_{6}$ \\
\hline $\mathrm{C}^{3+}(\%)$ & 4 & 0 & 0 & 0.01 & 0.11 & 0 & 0 \\
\hline $\mathrm{C}^{2+}(\%)$ & 6 & 30.9 & 49.6 & 64.3 & 73.8 & 31.9 & 29.5 \\
\hline $\mathrm{C}^{+}(\%)$ & 12 & 24.8 & 34.4 & 32.5 & 26.1 & 18.9 & 17.8 \\
\hline $\mathrm{C}_{3}{ }^{2+}(\%)$ & 18 & 2.7 & 5.0 & 0.52 & 0 & 8.4 & 13.0 \\
\hline $\mathrm{C}_{2}+(\%)^{\mathrm{b}}$ & 24 & $0^{c}$ & $0^{c}$ & 2.7 & 0.1 & 13.5 & 21.0 \\
\hline $\mathrm{C}_{3}+(\%)$ & 36 & 5.2 & 5.6 & 0.01 & 0 & 12.5 & 14.9 \\
\hline $\mathrm{C}_{4}+(\%)$ & 48 & 2.7 & 0.37 & 0 & 0 & 6.4 & 0 \\
\hline $\mathrm{C}_{5}+(\%)$ & 60 & 0.42 & 0.06 & 0 & 0 & 2.1 & 0 \\
\hline $\mathrm{BC}^{+}(\%)$ & 23 & - & - & - & - & - & 0.7 \\
\hline $\mathrm{CN}^{+}(\%)$ & 26 & 8.8 & 0 & - & - & - & 0 \\
\hline $\mathrm{SiC}_{2}{ }^{2+}(\%)$ & 26 & - & - & - & - & 5.7 & - \\
\hline $\mathrm{TiC}^{2+}(\%)$ & 30 & 24.4 & 5.0 & - & - & - & - \\
\hline $\mathrm{SiC}^{+}(\%)$ & 40 & - & - & - & - & 0.19 & - \\
\hline $\mathrm{SiC}_{2}+(\%)$ & 52 & - & - & - & - & 0.34 & - \\
\hline $\mathrm{MoC}^{2+}(\%)$ & 55 & - & - & - & - & - & 3.1 \\
\hline $\mathrm{SiC}_{3}+(\%)$ & 64 & - & - & - & - & 0.15 & - \\
\hline Total & & 100 & 100 & 100 & 100 & 100 & 100 \\
\hline
\end{tabular}

aVoltage pulsing.

bPartly also $\mathrm{C}_{4}{ }^{2+}$.

'Overlap with $\mathrm{Ti}^{2+}$. 
Table 4. Isotope ratios and carbon concentration obtained using only ${ }^{13} \mathrm{C}$ for $\mathrm{C}^{+}$ and $\mathrm{C}^{2+}$ compared to the result obtained using standard evaluation and the expected concentration. In the case of $\mathrm{Ti}(\mathrm{C}, \mathrm{N})$ a correction of the 24 Da peak was also made [11].

\begin{tabular}{|l|l|l|l|l|l|l|}
\hline & $\mathrm{Ti}(\mathrm{C}, \mathrm{N})$ & $\mathrm{Ti}_{2} \mathrm{AlC}$ & $\mathrm{WC}$ & $\mathrm{WC}^{\mathrm{a}}$ & $\mathrm{SiC}$ & $\mathrm{M}_{23} \mathrm{C}_{6}$ \\
\hline $\begin{array}{l}{ }^{13} \mathrm{C}^{2+} /{ }^{12} \mathrm{C}^{2+}(\%) \\
(1.08 \pm 0.08 \text { expected })^{\mathrm{b}}\end{array}$ & 1.65 & 1.62 & 1.21 & 1.34 & - & 1.87 \\
\hline $\begin{array}{l}{ }^{13} \mathrm{C}^{+} /{ }^{12} \mathrm{C}^{+}(\%) \\
(1.08 \pm 0.08 \text { expected })^{\mathrm{b}}\end{array}$ & 1.73 & 2.16 & 1.25 & 1.19 & - & 1.44 \\
\hline Standard method (\%) & 26.6 & 19.9 & 47.1 & 46.2 & 45.3 & $17.3^{\mathrm{c}}$ \\
\hline $\begin{array}{l}{ }^{13} \mathrm{C}-\text { method (\%) } \\
{ }^{13} \mathrm{C} \text { and 24 Da correction }\end{array}$ & 31.6 & - & - & - & - & - \\
\hline \begin{tabular}{l} 
Expected (\%) \\
\hline
\end{tabular} & 33.1 & $25^{\mathrm{d}}$ & 50 & 50 & 50 & 20.7 \\
\hline
\end{tabular}

aVoltage pulsing.

bBackground corrected counts.

cIncluding 2.1\% B.

dIncluding $\mathrm{N}$ and $\mathrm{O}$. 


\section{Figure caption}

Figure 1. Mass spectrum of SiC displaying wide peak tails. a) Entire spectrum. b) Lower part of spectrum. The peak shape is composed of a sharp peak at the correct position and a broad tail displaced towards higher mass-to-charge ratios (longer flight-times). Note the small boron peaks at 5, 5.5, 10 and $11 \mathrm{Da}$.

Figure 2. Mass spectrum of WC. a) Laser pulsed. b) Voltage pulsed. The mass spectra are similar. The mass resolution is slightly better in the voltage pulsed analysis. The $\mathrm{C}^{3+}$ peak at $4 \mathrm{Da}$ is larger when using voltage pulsing. Note the high signal-to-noise ratio of the ${ }^{13} \mathrm{C}$ peaks at 6.5 and $13 \mathrm{Da}$.

Figure 3. Mass spectra constructed using single and multiple events, respectively, from $\operatorname{Ti}(\mathrm{C}, \mathrm{N})$ obtained using a laser pulse energy of $0.2 \mathrm{~nJ}$. The amount of carbon is significantly larger in the multiple spectrum. Detailed mass spectra of this analysis can be found in Angseryd et al. [11]. 
Figure 1.
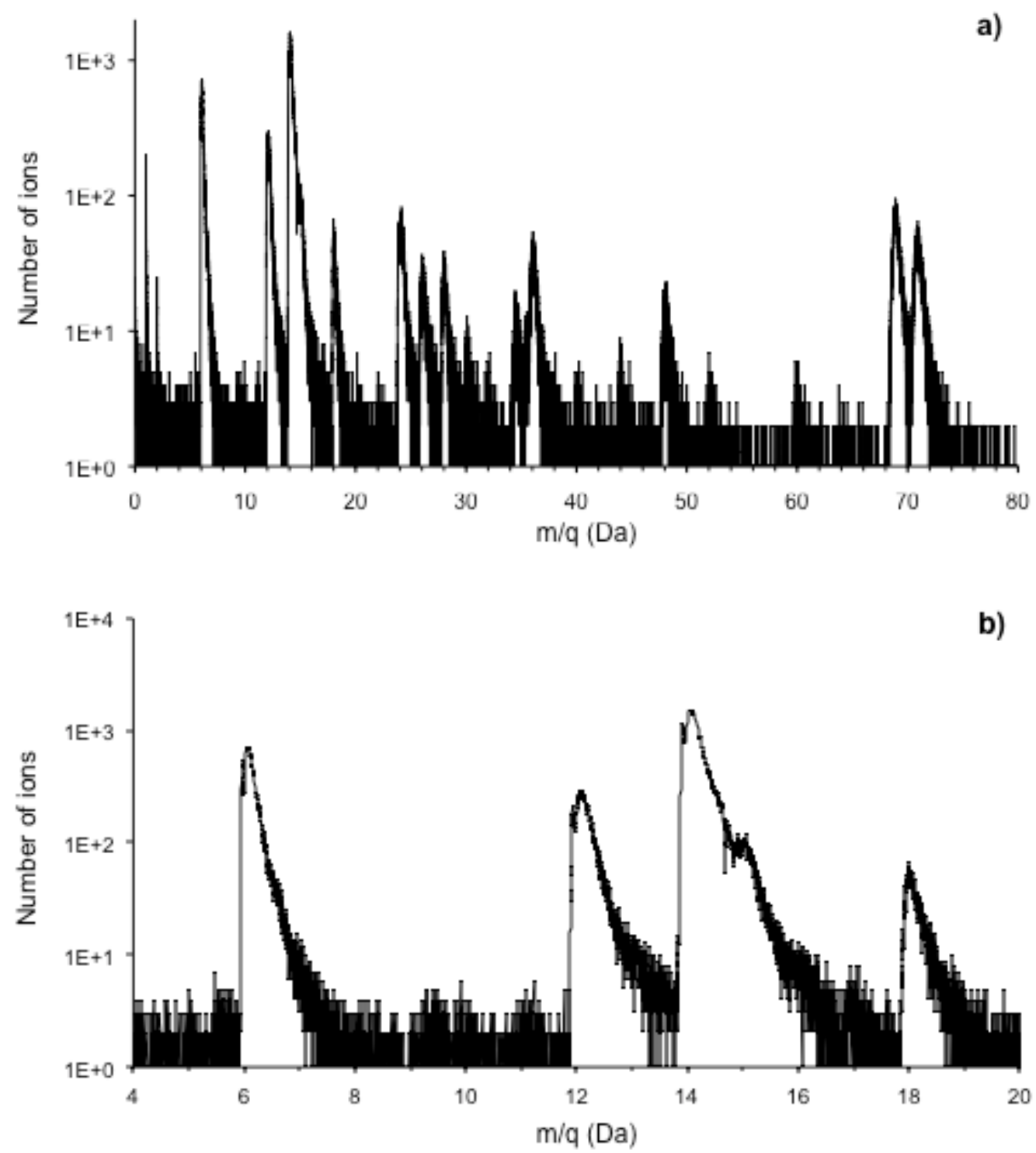
Figure 2.
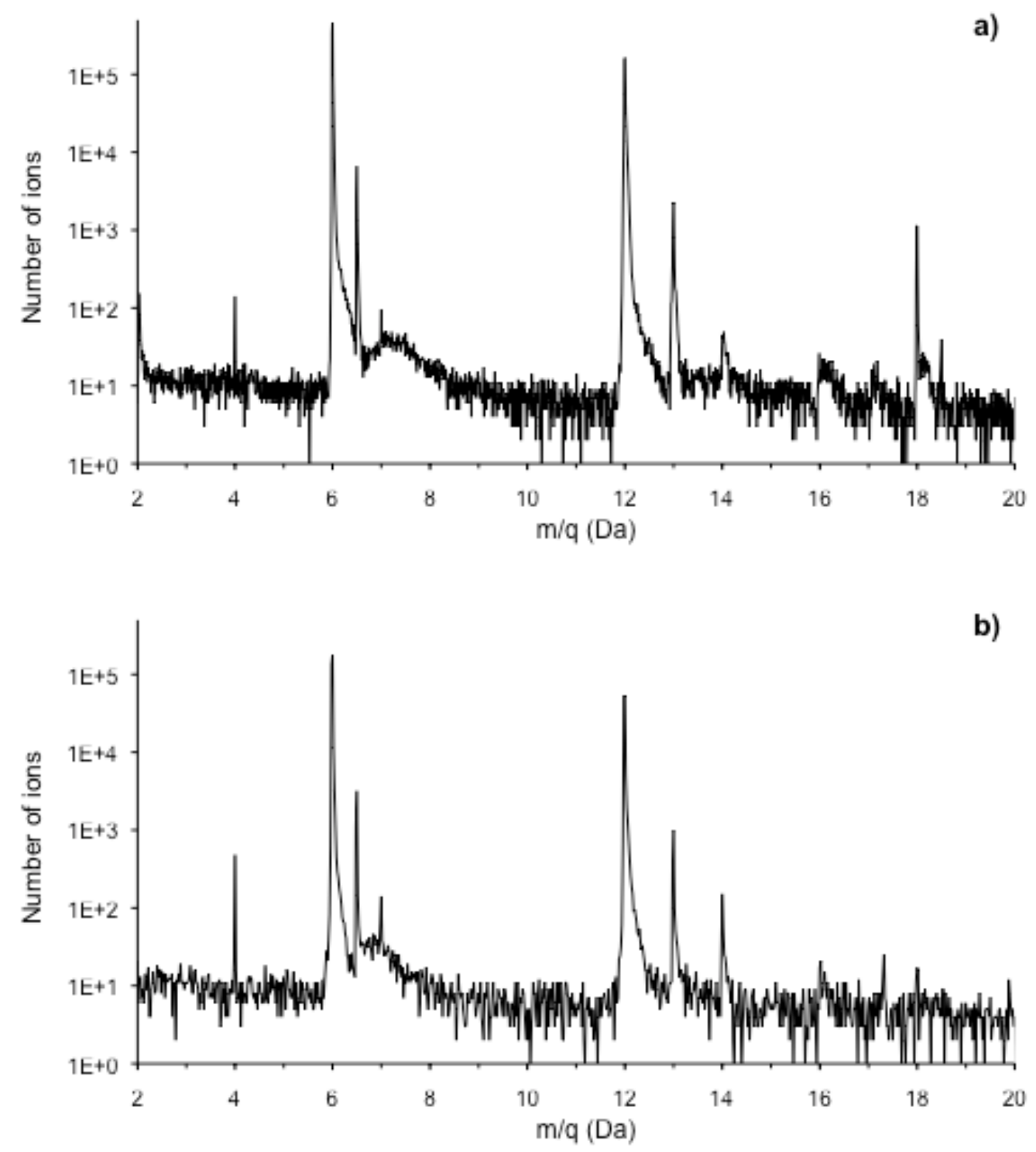
Figure 3.

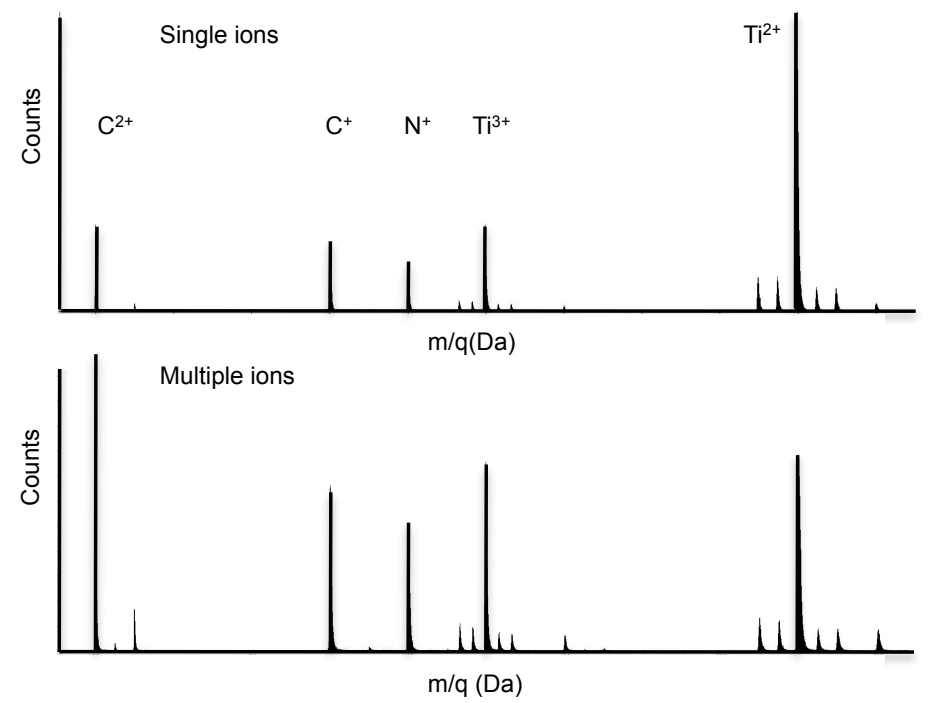

